\title{
Presentación del número especial, dossier: Germán Colmenares
}

El presente número especial, dossier: Germán Colmenares, representa una novedad editorial para la revista Artificios. Es la primera vez que se realiza un número especial y la primera vez que no se incluyen trabajos de estudiantes. El motivo de ello es la importancia para la historiografía colombiana del contenido que se presentará a continuación, especialmente para el público estudiantil, al contar con una serie de textos que pueden abrir nuevos debates o replantear viejas discusiones.

El lector podrá encontrar en este número especial 28 escritos de diversa índole; desde reseñas hasta planes de contenido que realizó el profesor Germán Colmenares en distintos momentos de su vida. Si bien algunos de los textos no son inéditos, sí son de difícil rastreo o reposan en los anaqueles de bibliotecas, dificultando su acceso. Así, el número funcionará también con un archivo digital, inmediato, para consultar material sobre la obra de Colmenares.

En adición, el lector podrá encontrar, además de una serie de cartas que muestran posiciones poco conocidas del profesor, una breve cronología sobre algunos de sus hitos académicos y profesionales, así como una propuesta de bibliografía donde se rescatan algunas de las principales obras y artículos.

Consideramos que la parte visual también es importante dentro de divulgación histórica. Por ello, incluimos una selección de documentos, de variadas temáticas, sobre Colmenares. Por ejemplo, el lector podrá observar algunos de su época como profesor visitante en la Universidad de Columbia; el acta de grado de la Universidad de París; reseñas internacionales sobre sus obras, entre otros.

Como se mencionó al principio, parecería irónico que una revista de estudiantes publique un número sin artículos de estudiantes, pero los textos acá presentes rescatan, proponen, replantean, discuten y analizan temáticas y preocupaciones que consideramos valiosas para la formación y el oficio del historiador; es allí donde se encuentra lo estudiantil del presente. Algunos de los textos publicados exhiben una cara poco conocida de Colmenares y dan insumos para comprender las estrategias investigativas del profesor. El injusto rótulo de "historiador colonial" que en ocasiones se le asigna invisibiliza - primordialmente en nosotros los estudiantes- la oportunidad de explorar otras aristas del historiador, además de las ya conocidas y divulgadas obras en torno a la caricatura, a las ideas políticas en el siglo XIX, a la historiografía en Hispanoamérica, etc.

En textos como Zorba el griego (inédito y acá incluido) se puede apreciar la pasión de Colmenares por otras actividades, como el cine. Otro ejemplo lo encontramos en los pasajes del plan de contenido de Bogotá, que además de presentar un rico modelo para abordar una historia a través de esta ciudad, se muestra como una oportunidad para ver la estructura organizativa de Colmenares. 
De igual forma, detrás del oficio del historiador existe una persona con puntos de vista e ideología definidas. Algunos de los textos contenidos en este número especial presentan una faceta que se aleja de las pretensiones "científicas" de la Historia, y permiten observar entre líneas las posiciones de Colmenares. En otros momentos, se verá abiertamente la perspectiva sobre asuntos políticos en Colmenares, como en Cultura y universidad, donde se nota la constante preocupación del profesor en torno a la universidad "liberal" y a los altibajos que sufren las ciencias humanas en un país como Colombia.

Las lecturas en torno a la Nueva Historia y sobre Germán Colmenares son algo a lo que se debe volver. La metodología, las preguntas y las discusiones que planteó el profesor Colmenares no sólo fueron innovadoras y refrescantes, sino que dejaron una huella indeleble en la historiografía colombiana.

A 30 años del fallecimiento de Germán Colmenares presentamos este aporte y esperamos que sea de goce y provecho para investigadores, estudiantes e interesados en general. Agradecemos los comentarios y consejos del profesor Renán Silva a través de todo el proceso editorial, además de su constante apoyo y generosidad en torno a la información y archivos de Colmenares; sin él, no hubiese sido posible la realización del presente dossier.

\section{Aclaraciones sobre el dossier}

Para la elaboración de este dossier se intentó mantener el estilo lo más parecido posible a los textos originales de los cuales se realizaron las transcripciones. Sin embargo, y siendo conscientes de la evolución que ha sufrido la lengua española - específicamente las normas que rigen su buen uso para facilitar la comunicación - en todos los años que han transcurrido desde que Germán Colmenares escribió los textos aquí presentados, se modificaron algunos aspectos ortotipográficos. Específicamente, se ajustó la acentuación ortográfica al uso actual; se suprimieron o añadieron algunos signos de puntuación para facilitar la comprensión de las oraciones; se ajustó el uso de las mayúsculas, minúsculas y cursivas a lo que indican las normas actuales definidas por la RAE - salvo algunos casos en donde se consideró que el modo en que Colmenares había hecho uso de estas tenía un trasfondo metalingüístico importante- - La sintaxis, por otra parte, se mantuvo igual.

De igual manera, y con el fin de mantener una coherencia con la pauta editorial de Artificios en lo que ha diagramación se refiere, se modificaron aspectos como el interlineado, la distribución de párrafos, el tipo y tamaño de letra, etc.; elementos que, en últimas, no alteran el sentido original de los textos, pero sí representan una mayor calidad visual para satisfacción de los lectores.

En cuanto al componente bibliográfico, Artificios optó por estandarizar - en la medida de lo posible - el sistema de citación al definido por el Chicago Manual of 
Style en su última edición. Esta decisión se tomó no porque la información contenida en el sistema utilizado por Colmenares - o quien haya editado los textos originalesestuviera mal, sino con el propósito, nuevamente, de tener un formato coherente con nuestra publicación. Algunas referencias, no obstante, quedaron sin uno que otro ítem necesario para su localización — en la mayoría de los casos, la casa editorial- Esto se debe a la dificultad que para el rastreo de dicha información significaron la antigüedad de algunos de los textos citados y la actual pandemia.

Por último, la revista Artificios aclara que todo el material citado y publicado en este dossier hace parte del archivo personal del profesor Renán Silva, y que recibió su autorización para su publicación y difusión.

Julián Galindo Zuluaga y Edward Aníbal Vásquez Guatapí Editor y asistente editorial 